IFAS Extension

\title{
Healthy Living: Taking Care from Head to Toe ${ }^{1}$
}

Jennifer Hillan ${ }^{2}$

If you have diabetes, there are some areas of your body that need ENAFS special attention. Your skin, eyes, teeth, gums, and feet are at risk for complications from diabetes. Read on to learn how you can take care of your body from head to toe!

\section{Skin}

Healthy skin is the first line of defense against infection. Tips for healthy skin:

$\checkmark$ Bathe or shower daily.

$\checkmark$ Towel-dry skin thoroughly.

$\checkmark$ Prevent dry skin. Use mild soaps and moisturizers. Use a humidifier in winter if the air is dry.

$\checkmark$ Don't put lotion between your toes, in your skin folds, or in your armpits. Use powder to keep these areas dry.

$\checkmark$ Treat cuts right away. Wash with soap and water and cover with a clean bandage. Use creams or ointments only if this has been recommended by your diabetes care team.

$\checkmark$ See a health care provider right away for major cuts, burns, or infections.

$\checkmark$ Use sunscreen.

$\checkmark$ See a dermatologist (skin doctor) about skin problems that can't be solved.

\section{Eyes}

Diabetic retinopathy (eye disease) is the most common complication of type 2 diabetes and is the leading cause of blindness in the U.S. Controlling blood glucose and blood pressure can help prevent or delay diabetic retinopathy.

See an eye doctor right away if you have:

- Blurry vision

- Trouble reading signs or books

- Double vision

- Pressure in your eyes

- Spots or floaters in your eyes

- Chronic red eyes

\section{See an eye doctor} (ophthalmologist or optometrist) every year to have an eye exam and catch eye disease early so it can be treated.

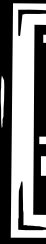

1. La versión en español de este documento es Vida Saludable: Cuidarse Desde la Cabeza a los Pies (FCS8821-Span). This document is FCS8821, one in a series of the Department of Family, Youth and Community Sciences, Florida Cooperative Extension Service, IFAS, University of Florida, Gainesville, FL 32611. First published: December 2006. Please visit the EDIS Website at http://edis.ifas.ufl.edu.

2. Jennifer Hillan, MSH, RD, LD/N, ENAFS nutrition educator, Department of Family, Youth and Community Sciences, Florida Cooperative Extension Service, Institute of Food and Agricultural Sciences, University of Florida, Gainesville, FL 32611.

The Institute of Food and Agricultural Sciences (IFAS) is an Equal Employment Opportunity - Affirmative Action Employer authorized to provide research, educational information and other services only to individuals and institutions that function without regard to race, creed, color, religion, age, disability, sex, sexual orientation, marital status, national origin, political opinions or affiliations. For information on obtaining other extension publications, contact your county Cooperative Extension Service office. Florida Cooperative Extension Service / Institute of Food and Agricultural Sciences / University of Florida / Larry R. Arrington, Dean 


\section{Teeth and Gums}

People with diabetes are at high risk for periodontal (gum) disease. This can lead to tooth loss. Tips for healthy teeth and gums:

$\checkmark$ Brush twice a day.

Floss daily.

See a dentist every six

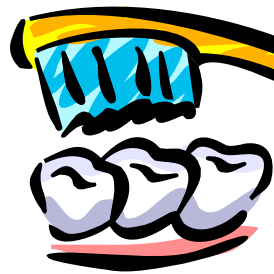
months

\section{Be sure you tell your dentist that you have diabetes.}

See your dentist if you have signs of gum disease, such as red, swollen, tender, or bleeding gums, bad breath, or changes in the way partial dentures or bridges fit.

\section{Did You Know...}

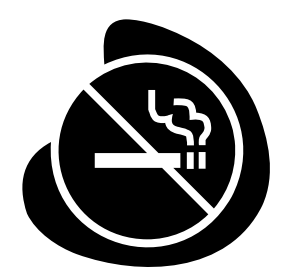

Smoking increases the risk of diabetes complications.

You can help prevent diabetes complications by not smoking and keeping your blood glucose level in a targeted range.

Talk to your diabetes care team about your targeted blood glucose level.

\section{Feet}

Foot sores (foot ulcers) can become infected, cause disability, and even lead to amputations. The good news is that foot sores can be prevented.

Have your feet checked annually by your health care provider and take care of your feet at home. Here are some ways to take care of your feet:

Inspect your feet daily for red spots, cuts, swelling, or blisters. Use a mirror to check the bottoms of your feet.

$\checkmark$ Wash your feet daily and dry them carefully, especially between your toes.

$\checkmark$ Keep your skin soft and smooth with a thin coat of lotion on the tops and bottoms of your feet, but not between your toes. Use a lotion that does not contain alcohol.

$\checkmark$ Trim toenails by trimming straight across and filing sharp edges with a nail file.

$\checkmark$ Wear shoes and socks rather than walking barefoot. Check the insides of shoes before putting them on.

$\checkmark$ Wear nonskid slippers in

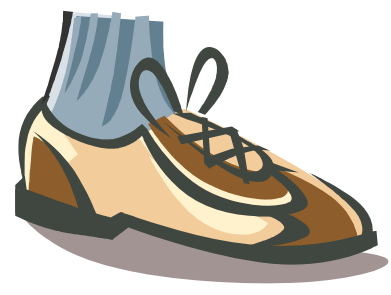
the house.

$\checkmark$ Wear clean socks and shoes that fit well.

$\checkmark$ Protect your feet from hot and cold.

$\checkmark$ Keep the blood flowing to your feet. Put your feet up when you sit; wiggle your toes and move your ankles. Don’t keep your legs crossed for long periods.

$\checkmark$ Talk to a health care provider if you develop open sores or infections, or if a toe becomes red and tender (this could be an ingrown toenail). 